\title{
Mobility and Entrepreneurship: Evaluating the Scope of Knowledge-Based Theories of Entrepreneurship
}

\author{
Lars Frederiksen, Karl Wennberg and Chanchal Balachandran
}

\section{Linköping University Post Print}

\section{Tweet}

N.B.: When citing this work, cite the original article.

Original Publication:

Lars Frederiksen, Karl Wennberg and Chanchal Balachandran, Mobility and Entrepreneurship: Evaluating the Scope of Knowledge-Based Theories of Entrepreneurship, 2016, Entrepreneurship: Theory \& Practice, (40), 2, 359-380.

http://dx.doi.org/10.1111/etap.12223

Copyright: 2016 The Authors. Entrepreneurship Theory and Practice published by Wiley Periodicals, Inc. on behalf of SAGE Publications Inc. This is an open access article under the terms of the Creative Commons Attribution-NonCommercial-NoDerivs License.

http://eu.wiley.com/WileyCDA/

Postprint available at: Linköping University Electronic Press http://urn.kb.se/resolve?urn=urn:nbn:se:liu:diva-126692 
(C) 2016 The Authors. Entrepreneurship Theory and Practice published by Wiley Periodicals, Inc. on behalf of SAGE Publications Inc. This is an open access article under the terms of the Creative Commons Attribution-NonCommercial-NoDerivs License, which permits use and distribution in any medium, provided the original work is properly cited, the use is non-commercial and no modifications or adaptations are made.

\title{
Mobility and
} Entrepreneurship: Evaluating the Scope of Knowledge-Based Theories of

\section{Entrepreneurship}

\author{
Lars Frederiksen \\ Karl Wennberg \\ Chanchal Balachandran
}

Knowledge-based theories of entrepreneurship infer transfer of knowledge from the effect of labor mobility on entrepreneurial entry. Yet, simple selection or situational mechanisms that do not imply knowledge transfer may influence entrepreneurial entry in similar ways. We argue that the extent to which such alternative mechanisms operate, labor mobility predicts entry but not subsequent performance for entrepreneurs. Analyses of matched employee-employer data from Sweden suggest that high rates of geographical and industry mobility increase individuals' likelihood of entrepreneurial entry but have no effects on their entrepreneurial performance. This indicates that the relationship between labor mobility and entrepreneurial entry do not necessarily imply knowledge transfer.

$\mathbf{T}_{\mathrm{h}}$ he flow of people between firms, industries and locations has been proposed as an important mechanism for transferring knowledge ${ }^{1}$ and is argued as important for innovation, firm demography, and entrepreneurship (e.g., Agarwal, Echambadi, Franco, \& Sarkar, 2004; Audretsch \& Keilback, 2007). For entrepreneurship research, individual mobility is central since it invokes the creation, transfer, and destruction of resources and capabilities in different markets (Wright, 2011). While knowledge-based theories propose knowledge flow as the key mechanism that connects labor mobility to entrepreneurial entry and performance (Agarwal, Audretsch, \& Sarkar, 2007; Helfat \& Lieberman, 2002), they are rarely challenged by alternative selection-based mechanisms such as individual "taste for variety" or "labor market misfits" (Åstebro, Chen, \& Thompson, 2011;

Please send correspondence to: Karl Wennberg, tel.: +46-705-10 53 66; email: karl.wennberg@liu.se. 1. Following theories of knowledge spillover, we refer to "knowledge" as an appropriable resource that is distinct from individual "skills" (Audretsch \& Keilback, 2007). 
Åstebro \& Thompson, 2011) and situational mechanisms ${ }^{2}$ such as individual opportunity cost (Amit, Muller, \& Cockburn, 1995; Sørensen \& Fassiotto, 2011). To the extent selection or situational factors explain the relationship between labor market mobility and entrepreneurship, knowledge-based theories that infer a treatment effect of knowledge transfer on entrepreneurship entry may be overestimated. While we expect to find a positive effect of labor market mobility on entrepreneurial entry through selection or situational mechanisms, we also expect to find an adverse or no effect on entrepreneurial performance if knowledge transfer is not the key mechanism underlying entrepreneurial entry. The basis of our argument is the assumption that knowledge is a key predictor of entrepreneurial performance (Agarwal et al., 2004; Dencker, Gruber, \& Shah, 2009; Helfat \& Lieberman; Klepper \& Sleeper, 2005). We test our arguments by analyzing the effect of different types of mobility on entrepreneurial entry and entrepreneurial performance relative to post-entry earnings.

We posit two research questions. The first question regards pre-founding characteristics of entrepreneurs: To what extent does prior industry and geographical mobility influence individuals' propensity to found a new firm? We argue that certain individual characteristics in combination with the opportunity structure they confront may explain entry into entrepreneurship. First, highly mobile individuals have a taste for variety or are misfits in the labor market that position them in constant search for new jobs. As jobs in established organizations tend to be standardized, individuals with a taste for variety are likely to enter entrepreneurship in search for different job experiences. Second, interindustry mobility provides opportunity for information arbitrage or results in low average industry specific experience, reducing the opportunity cost of switching from employment to entrepreneurship. Thus, a combination of selection and situational mechanisms may drive mobility into entrepreneurship without necessarily being accompanied by knowledge transfer.

To examine our claim that entry into entrepreneurship of highly mobile individuals may be driven by selection and situational mechanisms, we test the relationship between mobility and entrepreneurial performance. Knowledge-based theory of entrepreneurship posits individual mobility as a focal mechanism through which knowledge created in established organizations flows to newly founded firms (Agarwal et al., 2007; Franco \& Filson, 2006; Saxenian, 2006). If the flow of valuable knowledge is what drives entrepreneurship through employee mobility, then we should also expect systematic difference in the performance of entrepreneurs established by highly mobile individuals and those who experienced less mobility across jobs and industries. Alternatively, individuals who enter entrepreneurship simply because of their innate characteristics or the low opportunity cost in leaving paid employment do not necessarily transfer valuable knowledge predictive of entrepreneurial performance (Amit et al., 1995). These alternative explanations suggest that while mobile individuals are more likely to enter entrepreneurship, they do not necessarily exhibit better performance as entrepreneurs. Hence, our second question is: How does prior job mobility of firm founders affect entrepreneurial performance?

To investigate these questions, we use matched employee-employer data that follows individuals and firms in Sweden over 11 years. This enables us to pinpoint pre-founding effects on individuals arriving into entrepreneurship (e.g., spawning firm characteristics) and their career histories, allowing us to construct detailed measures of individual

2. Situational mechanisms pertain to the structure of opportunities an individual faces while selecting from a set of choices (Hedström \& Swedberg, 1998). As such, we do not assume any changes in the individual, for example, through learning, as a result of mobility. 
mobility (Åstebro \& Thompson, 2011). As we are interested in evaluating the scope of knowledge-based theories we zoom in on a subsample of industries where knowledge is of vital importance: knowledge-intensive industries. ${ }^{3}$ These industries serve as an ideal research setting to test our argument regarding knowledge flows, entrepreneurial entry, and performance. First, since knowledge is central to innovation and imitation in products and services as well as a key determinant of entrepreneurship (Delmar \& Wennberg, 2010), knowledge-intensive industry is a suitable setting in which to test our arguments. Second, prior studies on knowledge-based theories of entrepreneurship mostly relied on data from knowledge-intensive industries such as laser (Klepper \& Sleeper, 2005) or disk-drive industries (Agarwal et al., 2004) etc., whereby these industries serve as a natural setting for comparison. Third, focusing on this setting minimizes the unobserved heterogeneity issues surrounding industry differences in studying the rates of entrepreneurship (Eckhardt \& Shane, 2011). ${ }^{4}$

Our work seeks to bring clarity into the mechanisms that tie mobility to entrepreneurship. While knowledge-based theories of entrepreneurship posit knowledge transfer as a key mechanism that drives entrepreneurship (Acs, Braunerhjelm, Audretsch, \& Carlsson, 2009; Agarwal et al., 2007), we show that it may not necessarily always be true. We found that pre-founding job mobility affects the prevalence of entrepreneurial entry but not the earnings of entrepreneurs. Our results on differential effects of mobility on entrepreneurial entry and earnings provide a note of caution to researchers: Resources and knowledge may not be automatically inferred to flow from mobility without considering simple counterfactuals such as individuals' innate taste for variety (Åstebro \& Thompson, 2011) or the opportunity structure they confront (Sørensen \& Sharkey, 2014). Without attending to simple explanations related to selection or situational effects, models that attribute knowledge transfer as a mechanism that drive mobility into entrepreneurship will risk overestimation. As a corollary, our research also speaks to the expanding research on "firm spawning" (e.g., Klepper \& Sleeper, 2005; Sørensen \& Phillips, 2011), by showing that the "small firm spawning effect" documented in prior studies exercises differential effects on entrepreneurial entry and earnings in knowledge-intensive industries.

\section{Theory and Hypotheses}

We offer five hypotheses to probe different mechanisms related to the effect of labor market mobility of individuals on entrepreneurial entry and performance. We structure the hypotheses development in a way that highlights the limitations of inferring knowledge flows from the effect of mobility on entrepreneurship. We do this by contrasting knowledge-based explanations with alternative explanations based on selection and situational mechanisms, such as taste for variety, labor market misfits, and opportunity cost.

\section{Mobility and Entry into Entrepreneurship}

Why are individuals with a high degree of industry mobility more likely to found a firm than individuals with less mobility in their career history? Typical arguments refer to knowledge accumulation and spillover effects as mechanisms by which highly mobile

3. Please see the Methods section and the Appendix for definitions and descriptions of these industries.

4. While the data allow us to investigate instances where prospective entrepreneurs venture into other industries (Agarwal et al., 2004), our results are not exhaustive to entrepreneurship in all potential industries. 
individuals enter entrepreneurship (e.g., Agarwal et al., 2004). Yet, part of the reason can be attributed to the possibility that certain individual characteristics such as taste for variety are correlated with their propensity for mobility. Ghiselli (1974, p. 81) suggests the idea of the hobo effect as "...the periodic itch to move from a job in one place to some other job in some other place." If individuals with a high degree of mobility are primarily driven by a taste for variety, they may have a psychological bias against staying in regular jobs for long periods of time (Astebro \& Thompson, 2011). As a result of constant search for varied experience, they also exhibit a certain degree of misfit in the labor market. Such underlying individual characteristics could affect individuals' choice for entrepreneurial entry, working independently from a change in their knowledge pool. Hence, selection on unobserved traits may explain both mobility and entry into entrepreneurship without any treatment effect of knowledge transfer.

Mobility and entry into entrepreneurship may also be codetermined by situational mechanisms such as individual opportunity structure. First, individuals who transfer between industries are more likely to identify niche opportunities in the market as well as to engage in arbitrage of information, which is asymmetrically distributed in society (Shane, 2000). Aldrich and Kenworthy (1999, p. 20) argue that “... innovative start-ups are often the result of creative experimentation with new ideas by outsiders to an industry. Experience guides the choice of a domain for exploration, but indifference to industry routines and norms gives an outsider the freedom to break free of the cognitive constraints on incumbents." As mobility helps individuals to identify opportunities, we can expect a positive effect of mobility on entrepreneurial entry without actually having any changes in their knowledge pool.

Second, highly mobile individuals may lower opportunity cost in entering entrepreneurship (Amit et al., 1995). While moving from one industry to another, individuals forego industry-specific skills that would otherwise contribute to their human capital. The loss of human capital associated with switching industries reduces their seniority for which they may incur a wage penalty in the labor market. As a result, highly mobile individuals have less incentive to search for jobs in established firms, resulting in increased mobility into entrepreneurship.

Third, situational mechanisms (e.g., opportunity for information arbitrage, opportunity cost) may interact with selection mechanisms (e.g., taste for variety, labor market misfits) in driving entry into entrepreneurship without any knowledge diffusion. For instance, opportunity for arbitrage is more likely to be utilized by individuals with a taste for variety. They are less likely to be satisfied with accumulating skills and competences related to a particular industry. Continuous search for different experiences would predispose them to experiment with entrepreneurship because the set of available jobs in an industry may not remain attractive long enough for such individuals. The innate taste for varied experience will likely make them misfits in any labor market that operates with institutionally defined roles and knowledge structures (e.g., professional boundaries), making them more susceptible to respond to opportunity structures. Taken together we posit:

5. Ghiselli (1974, p. 81) continues: "This urge to move seems not to result from organized or logical thought, but rather would appear more akin to raw, surging, internal impulses, perhaps not unlike those that cause birds to migrate. Floaters readily provide socially acceptable explanations for their peripatetic activity, but under careful examination these explanations turn out to be little more than rationalizations. The simple fact is that after being in one place for a matter of months, or perhaps a year or so, depending on the strength and periodicity of his itch, the individual is impelled to pack up and move to another place and another job." 
Hypothesis 1: The number of different industries within which an individual has held a job is positively related to an individual's likelihood of entrepreneurial entry.

To further investigate the effect of mobility on entrepreneurial entry, we hypothesize another dimension of mobility - across geographical regions. Geographical mobility as a mechanism for knowledge spillovers in entrepreneurship is primarily studied from the network or internationalization perspectives: for example, how entrepreneurs starting businesses in their local environment can draw on local resources and relationships (Stuart \& Sørenson, 2003) or how immigrants and expatriates who move from, or back to, their home country set up businesses in new regions (Saxenian, 2006). As such, we know less about more general types of geographic mobility - that of individuals within national boundaries - as a mechanism regulating the propensity for entrepreneurial entry. Out-ofarea moves entail disruption to social resources and roles, altering the locations of life and work. Such moves are often provoked by dissatisfaction with current work or life states, or by the lure of more attractive work or life situations elsewhere. This typically means that while some individuals move to start businesses in remote regions where industry conditions are fertile, most entrepreneurs choose to start businesses in the region in which their social network is embedded (Cooper, 1985).

The social network perspective-frequent in studies of transnational entrepreneurship as well as on entrepreneurial opportunity discovery-suggests two types of mechanisms whereby geographical mobility may trigger entrepreneurship: First, moving out of their original location exposes individuals to new types of opportunities, which they may be able to recognize and develop. The movement from far away may enhance the possibility for bringing new skills and ideas into a context that may value such "foreign" and different products or services (Davidsson, 2004).

Second, a diverse geographical background with time spent in a number of locations provides opportunities for building an expanded social network in terms of "weak ties" to a variety of potential customers, suppliers, and other stakeholder. Newcomers in a region that have a significant range of weak ties are ideally positioned for information arbitrage and thereby the discovery of entrepreneurial opportunities (Kim \& Aldrich, 2007). A high degree of geographical mobility may thus enhance individuals' network resources as well as their cognitive base for identifying opportunities (Saxenian, 2006), leading us to suggest:

Hypothesis 2a: The number of moves between different geographic areas is positively related to an individual's likelihood of entrepreneurial entry.

Hypothesis 2b: The distance of geographic moves is positively related to an individual's likelihood of entrepreneurial entry.

\section{Mobility and Entrepreneurial Performance}

If mobility between different industries or locations leads to accumulation of knowledge, mobility should not only influence the likelihood of entrepreneurial entry but could also influence entrepreneurial performance. Given the counterfactual possibility that reasons for mobility are driven by situational or selection mechanisms, examining the effects 
of mobility on entrepreneurial performance provides an interesting litmus test of knowledge-based arguments. If mobility is strongly associated with some other background variable that does not affect entrepreneurial success, we would expect mobility to exhibit a positive effect on entrepreneurial entry but exhibit no effect — or even an adverse effect - on entrepreneurial earning.

If movement across different industries and locations is prompted by an individual's taste for variety, this may, however, have detrimental effects on entrepreneurial capabilities from too frequent job shifts (Elfenbein, Hamilton, \& Zenger, 2010). In fact, this may be detrimental for human capital accumulation, since a fair length of tenure is required to learn any job and thus accumulate knowledge. Better performance in entrepreneurship usually requires in-depth knowledge regarding the needs of the market and meeting those demands with sufficient quality in technical or product-related competences, skills that are often acquired through education or accumulated industry experience (Dahl \& Reichstein, 2007). For instance, in a study of the invention of three-dimensional (3D) printing, Shane (2000) argues that exploitation of entrepreneurial opportunity in 3D printing is influenced by the extent to which entrepreneurs acquired prior knowledge related to the technology and their familiarity with market needs and potential customers.

Yet another alternative explanation is that mobile individuals may have difficulties in finding a good "match" in either paid employment or entrepreneurship (Åstebro et al., 2011). They simply may have abilities that are ill-suited for employment or have less ability to work well with others. Both alternative explanations (i.e., taste for variety and labor market misfits) suggest that if knowledge is not driving the mobility-entrepreneurship relationship, we would observe mobile individuals to be more likely to enter entrepreneurship but not exhibit higher performance:

Hypothesis 3a: The number of different industries within which an entrepreneur has held a job has a negative or zero association with entrepreneurial performance.

Hypothesis 3b: The number of moves between different geographic areas made by an entrepreneur has a negative or zero association with entrepreneurial performance.

\section{Data and Methods}

Responding to pleas in entrepreneurship research to use longitudinal data that does not depend on success or recall bias we employ an extract from a set of two matched longitudinal data sources on the Swedish labor market to test our hypotheses. Our data come from governmental registers maintained for research purposes by Statistics Sweden. The first source is LISA - a database on all legal residents of Sweden over the age of 16 from 1989 onwards. It contains demographic and financial information from a number of sources, including individual tax statements, financial records, birthplace registries, and school records. The second source is RAMS - an annual mandatory survey of the total population of all legal residents matched to firms having at least one employee or earning a profit. This source offers information on employment, industrial structures, and also tracks flows in the labor market.

The sample frame of our database is the complete set of individuals and firms in knowledge-intensive industries, according to Eurostat and OECD classifications of such sectors (Götzfried, 2004). In total, twenty-two 5-digit industry codes equivalent to the 
U.S. Standard Industrial Classification (SIC) system are included in the sample, comprising $33 \%$ of the Swedish economy but over $40 \%$ of GDP (see the Appendix). While only individuals active in these industries at any time from 1989 to 2002 are included, we have complete labor market history on these individuals regardless of their prior employment industry, and we continue to observe individuals that move to other industries. Hence, while our inferences with regards to entrepreneurial entry and earnings are limited to ventures in knowledge-intensive industries, the measures of mobility are unbiased. These matched databases enable us to observe transitions in labor status and the characteristics of firms in which individuals have been employed and/or founded. Important for our purposes, the data permit us to observe the career trajectory of individuals transcending from employment into entrepreneurship. ${ }^{6}$

The construction of the sample for analysis was based on a set of restrictions from the LISA data set to eliminate sources of heterogeneity. First, to avoid potential biases from situations where gender may impact family choices on entrepreneurship entry and performance, we included only men in our sample. Second, we exclude those with any experience in entrepreneurship between 1989 and 1994, since the dynamics of serial entrepreneurship is known to be distinct from that of novice entrepreneurs (Ucbasaran, Westhead, \& Wright, 2009), which could bias our estimates of mobility. Third, to develop measures of pre-entry labor market experience we eliminate observations prior to 1994 (Sørensen \& Phillips, 2011). Finally, to avoid problems of retirement and full-time education, we eliminate all individuals who exit the labor force any time between 1995 and 2001, and further eliminate all below age 23 or above age 65 in any of the years 1994 to 2001.

In total, 230,362 individuals fulfill our sample criteria. We follow these from 1994 until 2002 and include their labor market history between 1989 and 1994 to construct predictor and control variables. The long time period of the data addresses the challenge in studying career histories and mobility over time (Carroll \& Mosakowski, 1987).

\section{Dependent Variables}

We model two key outcomes in entrepreneurship research: entrepreneurial entry in the form of creating a new legal organization (Shane, 2009) and entrepreneurial performance measured as firm founder's income from entrepreneurship.

Following earlier research, the first dependent variable, entry, is a dichotomous indicator of whether an individual in our population was active in entrepreneurship during year $t$, but not in the preceding year (Sørensen \& Phillips, 2011). We define an entrepreneur as an individual who reports residual income from a company in which she works full time. To exclude the prevalence of part-time or "hybrid" entrepreneurs (Folta, Delmar, \& Wennberg, 2010) we include only firms where the individual also holds the majority ownership stake.

The second dependent variable is Entrepreneurial performance. We measure performance using entrepreneurial earnings. Prior studies have exhibited difficulties in measuring firm performance since performance in entrepreneurship is difficult to collect for discontinued ventures. Performance has often been ignored or measured indirectly as "financial leverage" (Bates, 1990) or "money taken out of the business" (Gimeno, Folta, Cooper, \& Woo, 1997). These are imperfect measures since entrepreneurs often choose to

6. A somewhat similar approach is taken by papers investigating related issues using generalizable longitudinal data on the U.S. (Özcan \& Reichstein, 2009) or Danish labor markets (Nanda \& Sørensen, 2010). 
forego current benefits in preference of reinvesting the money. We overcome this problem by using the multi-level nature of the data, where firm-level performance variables can be constructed according to Hamilton's (2000) definition of entrepreneurial earnings as (revenues - expenses $=$ money taken out + retained earnings), where performance is measured as the sum of money taken out + retained earnings. The measure was highly skewed and we therefore transformed it into log form.

Job Switch. To account for the possibility that mobility may be related to any type of job switch (including entrepreneurial entry) we also model Job switch, defined as leaving paid employment and moving to another employer between year $t$ and the preceding year. This provides a counterfactual to the test of our mobility variables for entrepreneurial entry.

\section{Independent Variables}

Industry Mobility. Movement across industrial sectors exposes the individual to a wider range of tasks and organizational models, thus extending the individual's experience in terms of scope. Using LISA, we count the number of job moves between different industry domains (i.e., across 5-digit SIC codes) an individual has experienced during the past 5 years. $^{7}$

LISA includes information on individuals' county of residence and how often addresses are updated. We used this information to create two variables. Geographical mobility is an ordinal-scaled variable counting the number of times an individual has moved between municipalities during the past 5 years. ${ }^{8}$ Geographical mobility distance measures the accumulated distance that an individual has moved during the past 5 years, using a variant of the geographic dispersion index developed by Sørenson and Audia (2000). A higher value of this measure implies high geographical mobility; lower values imply low mobility.

\section{Control Variables}

Our argument that mobility matters for entrepreneurship hinges on the proposition that it is not exclusively either: (1) the traditional time-invariant variables like gender or age, or (2) human and social capital parameters such as education levels, experience of previous entrepreneurial endeavors, having entrepreneurial parents, or exposure to particular peers or even (3) the life-course variables of marriage and children-that best predict the potential for entrepreneurship. To address concerns that our results are caused by

\footnotetext{
7. We included a squared term to investigate the potential nonlinear effects of industry mobility to further probe the "taste for variety" argument. This variable was not statistically significant but highly collinear with the industry mobility variable. We therefore report models without the nonlinear effect of industry mobility as not to overfit our model and induce risks of multicolinearity. As a robustness test, we categorized industry mobility only when shifts occurred in two-digit SIC codes. This decreases the variable's mean value from 1.36 to 1.03 and the maximum value from 11 to 7 but in our Cox models it was still a positively associated with entrepreneurial entry $(p>.001)$ but not significantly related to performance $(p<.10)$.

8. Using industry and geographic mobility as independent variables has an additional advantage in disentangling entrepreneurship entry from being a random outcome of mobility in general. While industry switches will alter the opportunity cost of entrepreneurship entry because of the loss of industry-specific human capital, geographic mobility is weakly correlated with job mobility in our setting (Korpi, Clark, \& Malmberg, 2011).
} 
other effects we include a number of additional control variables, which have been shown in previous studies to influence entrepreneurial entry and performance.

Employer size is found to influence the probability of entrepreneurial entry (Sørensen, 2007a). We measure size of prior employer organization with five dummy variables where the first indicates employer size 1-25, the second indicates employer size 26-100, the third employer size 101-1,000, the fourth employer size 1,001-5,000, and the fifth (omitted as baseline in regression) for employer size 5,000+. Employer age is measured with two dummy variables since our data is left censored at 1989. The first denotes employer age $0-2$ and the second denotes employer age 3-6. Work tenure is captured by a variable measuring the number of years of employment since entering "time at risk"i.e., 1994. By nature of the sample set-up, this key variable is not truncated. Hence, the variable takes the value between 1 and 5. We also include its squared effect: work tenure squared, to control for potential nonlinear effects. ${ }^{9}$ We include a variable Years of education to operationalize general human capital (Arum \& Müller, 2004; Brüderl, Preisendörfer, \& Ziegler, 1992). To remedy the risk of our mobility variable being confounded with the accumulation of specific human capital, we created the variable Industry experience, measured as number of years of experience in a focal industry (SIC-3 level equivalent) during the 5 most recent years of an individuals' career. The variable was thus truncated above 5. Truncation of independent variables risks underestimating the effect of the variance in the variable at the positive side of the distribution and increases the likelihood of type-two errors. However, only $3 \%$ of the sample had 5 years or more industry experience, indicating low risk of systematic bias. ${ }^{10}$

The choice to set up a new firm may be affected by parental heritage; that is, a child following the career footsteps of his or her parents (Evans \& Leighton, 1989). Parental heritage is known to affect entrepreneurial entry through transfer of human capital, exposure to role models, and inheritance of genetic disposition (Aldrich \& Ruef, 2006; Sørensen, 2007b). To control for this we include a dummy variable, Parents' entrepreneurship, measuring exposure to entrepreneurship during upbringing. This variable is derived from Statistics Sweden's cross-generation database that provides data on the labor market activities of all Swedish residents living in the same household from 1960 to 2002.

Children: A time-variant ordinal variable measures number of children in the household. Married: We used information on household composition from LISA to construct a dummy variable that equals 1 if the individual is married or cohabiting. Ethnic background: Immigrants are known to have higher probabilities of entering entrepreneurship (Arum \& Müller, 2004). We measure immigration with a dummy that takes the value 0 for Nordic (i.e., Scandinavian) and 1= other. Wage as employee is measured in logarithmic form to control for the opportunity costs of employment (Özcan \& Reichstein, 2009). Spouse wage is measured in logarithmic form to control for the fact that household resources are often pooled in entrepreneurial firms (Folta et al., 2010). Household wealth is a dummy variable taking the value " 1 " if a person has assets (including a house) exceeding \$110,000, which controls for the potential of liquidity affecting likelihood of entry. All individuals living in Sweden receive a personal identification number based on their date of birth. We used this information to calculate individual's Age (in years).

9. The squared term of work tenure is highly collinear with the constitutive term. In unreported modelsavailable on request-we therefore included only the constitutive term, with results unchanged.

10. As robustness checks we fitted unreported models including a dummy variable for individuals with $6+$ years of experience. This slightly decreased effects sizes but significance levels were still well below $5 \%$. 
Our theory posits an alternative to knowledge spillover argument for departures from wage work to entrepreneurship, yet we cannot distinguish between departures driven by a "taste for variety" and low opportunity costs in terms of low/stagnating wages. To proxy for the potential of necessity-driven departures from employment to entrepreneurship by employees, we include the control variable Wage trend, coded as an accumulated 3-year change in wage. For most individuals, this variable takes a positive value but for some it takes a negative value, indicating falling wages. This variable approximates for the opportunity costs of leaving paid employment for entrepreneurship. Inverse Mills Ratio; In our data, 2,549 individuals engage in entrepreneurship at any time during the period 1995 to 2002. Our analysis of entrepreneurial performance is based solely on these individuals, who constitute a subsample of the overall group of potential entrepreneurs. It is possible that this subsample exhibits some specific characteristics that simultaneously affect their likelihood of engaging in entrepreneurship and their performance as entrepreneurs, raising a risk that coefficients that show a statistically significant relationship with subsequent performance will be biased. We approached that aspect of the subsample by using a two-step Heckman process where the estimates of entrepreneurial entry in Table 3 are used as a self-selection control for entry when estimating the performance equation. We used Lee's (1983) generalization of the Heckman selection model to create a selection-correction variable (Inverse Mills Ratio) from the predicted estimates of entrepreneurial entry in Table 3. As instrument for the selection equation, we excluded the variables: Wage trend, Wage, and Spouse wage, all of which were significantly related to likelihood of entry but only very weakly related to entrepreneurial performance. Introducing the Inverse Mills Ratio in Table 4 lowers the risk of observing spurious results based on sample selection bias. All predictor and control variables were lagged 1 year to avoid simultaneity bias.

\section{Estimation Strategy}

Our first set of analyses uses competing hazard rate analysis to estimate models of entrepreneurial entry, compared to taking a new job (Brüderl et al., 1992). The flexible Cox specification is used, which does not require specific assumptions in regards to the distribution of the hazard rate (Lancaster, 1979). ${ }^{11}$ Cox regression models time $(t)$ as a function of an underlying hazard $h$ and a set of exponentiated beta coefficients $\left(\beta_{i j}\right)$ and covariates $(x)$ for individual at year. The baseline hazard $h$ corresponds to the case where all covariates (x) equals 0 , and is shifted up or down proportionally with changes in the covariates:

$$
h(t)=h_{0}(t) \exp \left(\beta_{i j} x_{i j}\right)
$$

The standard Cox model does not account for the potential of unobservables in the data. The presence of unobserved heterogeneity is conceivable in entrepreneurship due to the unobservable nature of entrepreneurial skills, which may be uncorrelated with observable skills (Parker, 2005; Shane, 2000). ${ }^{12}$ The problem of unobserved heterogeneity-called

11. We plotted the data to ensure the proportional-hazards assumptions were met. We also plotted baseline Kaplan-Meier survival curves for all hypothesized variables and compared these with the curves predicted by the Cox models to ensure that predicted effects did not deviate abnormally from observed values.

12. Our sample is designed to restrict heterogeneity in, e.g., prior entrepreneurial experiences and gender to test the theoretical variables of mobility and prior employment. We still cannot rule out the presence of unobserved heterogeneity. A common remedy to the problem of unobserved heterogeneity is to estimate models with individual fixed effects. However, by the nature of our design individuals may enter entrepreneurship only once and as a consequence, fixed effects cannot be utilized (Sørensen \& Phillips, 2011). 
"frailty" in hazard analysis-tends to stem from incomplete model specification where models with no frailty are at risk overestimating negative time dependence in the hazard rate, as well as underestimating the proportionate effect on the hazard from a change in the predictors (Lancaster, 1979). Hazard models can be extended to account for heterogeneity by incorporating frailty as a latent random effect that enters multiplicatively on the hazard function. We try to accommodate the existence of unobserved heterogeneity (frailty) by estimating a version of the Cox model which incorporates a gamma distributed random effects term with mean zero to summarize unobserved frailty connected to each individual spell. The random effects are specified to arise randomly but stratified according to some observable group characteristics that may be correlated with unobservable characteristics. Entrepreneurial ability is generally believed to be correlated with education and other human capital variables. We, therefore, stratified individuals according to years of education (17 groups) since educational level is known to be correlated with both IQ and unobserved ability (Van Praag \& Cramer, 2001). ${ }^{13}$ In the model estimated, the random effects term $(v)$ describes unexplained heterogeneity as the influence of unobserved risk factors in the model as:

$$
h_{i j}(t)=h_{0}(t) \exp \left(\beta_{i j} x_{i j}+v_{i}\right)
$$

In the regression outputs, all coefficients are displayed as hazard rates (HR), which ease interpretation of these as marginal effects. These we attend to for each hypothesis. A coefficient of 1.01 indicates that a one-unit increase in covariate $x$ increases the likelihood of the outcome variable (entry or exit) with $1 \%$, while .99 indicate that a one-unit increase in covariate $x$ decreases the likelihood of the outcome variable with $1 \%$.

In the second set of analyses, we apply linear regression models to examine the effects of theoretically motivated mobility variables for entrepreneurial performance. These models are estimated using two different specifications, pooled OLS, and panel data models estimated with random effects. Both models were estimated with standard errors clustered around individuals to accommodate for autocorrelation.

\section{Results}

Means, standard deviations, and correlations are presented in Table 1. The correlation matrix is displayed in Table 2. Correlations were generally found to range between 0.01 and 0.4. This indicates that multicollinearity is not a major problem. Table 3 shows competing hazard (Cox) models with frailty for entrepreneurial entry to investigate the relationship between mobility and entrepreneurial entry. To account for the possibility that mobility may be related to any type of job switch (including entrepreneurial entry) we also model Job switch, defined as leaving paid employment and moving to another employer during a year. This provides a counterfactual to the test of our mobility variables for entrepreneurial entry. For each hypothesized effect on the relationships between prior career mobility and entrepreneurial entry, we thus estimate competing hazard

13. In unreported models_-available on request—we also stratified frailty by employer size (6 groups) as well as deciles of prior wages (10 groups), the latter being a rough proxy of returns to ability. Direction and significance levels of all hypothesized effects remained identical, although size effects varied and the estimated frailty variance theta $(\theta)$ was not significantly different from zero in the models stratified by employer size. 
Variable Means and Modal Values

\begin{tabular}{|c|c|c|c|c|}
\hline Variable & Mean & SD & Min & Max \\
\hline Entry & .01 & .04 & 0 & 1 \\
\hline Job switch & .17 & .37 & 0 & 1 \\
\hline Log (ent. earnings) & 10.08 & 6.12 & 0 & 15.34 \\
\hline Years of education & 9.88 & 6.06 & 0 & 20 \\
\hline Industry experience & .26 & 1.06 & 0 & 5.91 \\
\hline Parents' entrepreneurship & .10 & .04 & 0 & 1 \\
\hline Children & .89 & 1.09 & 0 & 10 \\
\hline Married & .53 & .50 & 0 & 1 \\
\hline Age & 42.00 & 11.32 & 23 & 65 \\
\hline Nordic & .90 & .30 & 0 & 1 \\
\hline Wage (log) & 12.17 & 1.70 & 0 & 17.18 \\
\hline Spouse wage (log) & .21 & 1.54 & 0 & 14.30 \\
\hline Household wealth (dummy) & .07 & .25 & 0 & 1 \\
\hline Work tenure & .69 & .69 & 0 & 5 \\
\hline Work tenure2 & .96 & 2.28 & 0 & 25 \\
\hline Industry mobility & 1.36 & 1.58 & 0 & 11 \\
\hline Geographical mobility & .34 & .73 & 0 & 9 \\
\hline Geographical mobility distance & 12.15 & 1.84 & 0 & 17.18 \\
\hline Wage trend/1,000 & 13.08 & 8.10 & 42.32 & -23.31 \\
\hline Employer age (0-2) & .08 & .27 & 0 & 1 \\
\hline Employer age (3-6) & .05 & .21 & 0 & 1 \\
\hline Employer size 1-25 & .12 & .32 & 0 & 1 \\
\hline Employer size 26-100 & .09 & .28 & 0 & 1 \\
\hline Employer size 101-1,000 & .21 & .41 & 0 & 1 \\
\hline Employer size 1,001-5,000 & .25 & .43 & 0 & 1 \\
\hline Employer size 5,000+ & .34 & .47 & 0 & 1 \\
\hline
\end{tabular}

models to compare the effects against a model testing the same variables for the likelihood of switching jobs (van Praag, 2003).

The bottom row of both models in Table 3 displays log-likelihood and BIC values as tests of model fit. Comparisons with unreported (baseline) models indicate significant improvement in model fit when the variables of mobility and employer size and age are added. The estimated frailty variance theta $(\theta)$ is tested with a log-likelihood ratio (LR) which compares the frailty model to the standard Cox. The model for entrepreneurial entry in Table 3 shows an LR statistic of $54.19(p>.001)$, indicating significant unobserved heterogeneity and that the frailty model is preferable to the standard Cox, as do the comparative model testing the effects on our predictor variables for job switch (LR test: 201.30, $p>.001$ ).

Under the heading "mobility effects" in Table 3, we first examine the hypothesized effects of the number of different industries within which the individual has held a job upon entrepreneurial entry. The coefficient for Industry mobility in Table 3 is positively associated with entrepreneurial entry $(p>.001)$. The hazard rate of 1.268 indicates that for each additional industry switch in the preceding 5 years, the likelihood of entering entrepreneurship increases by $26.8 \%$. This confirms hypothesis 1 . When comparing this to the coefficient in column two of Table 3, we see that past Industry mobility is negatively associated with subsequent likelihood of job switch $(p>.01)$. This indicates that the effect of industry mobility on entrepreneurship is not merely a pattern related to overall likelihood of switching jobs in general. 


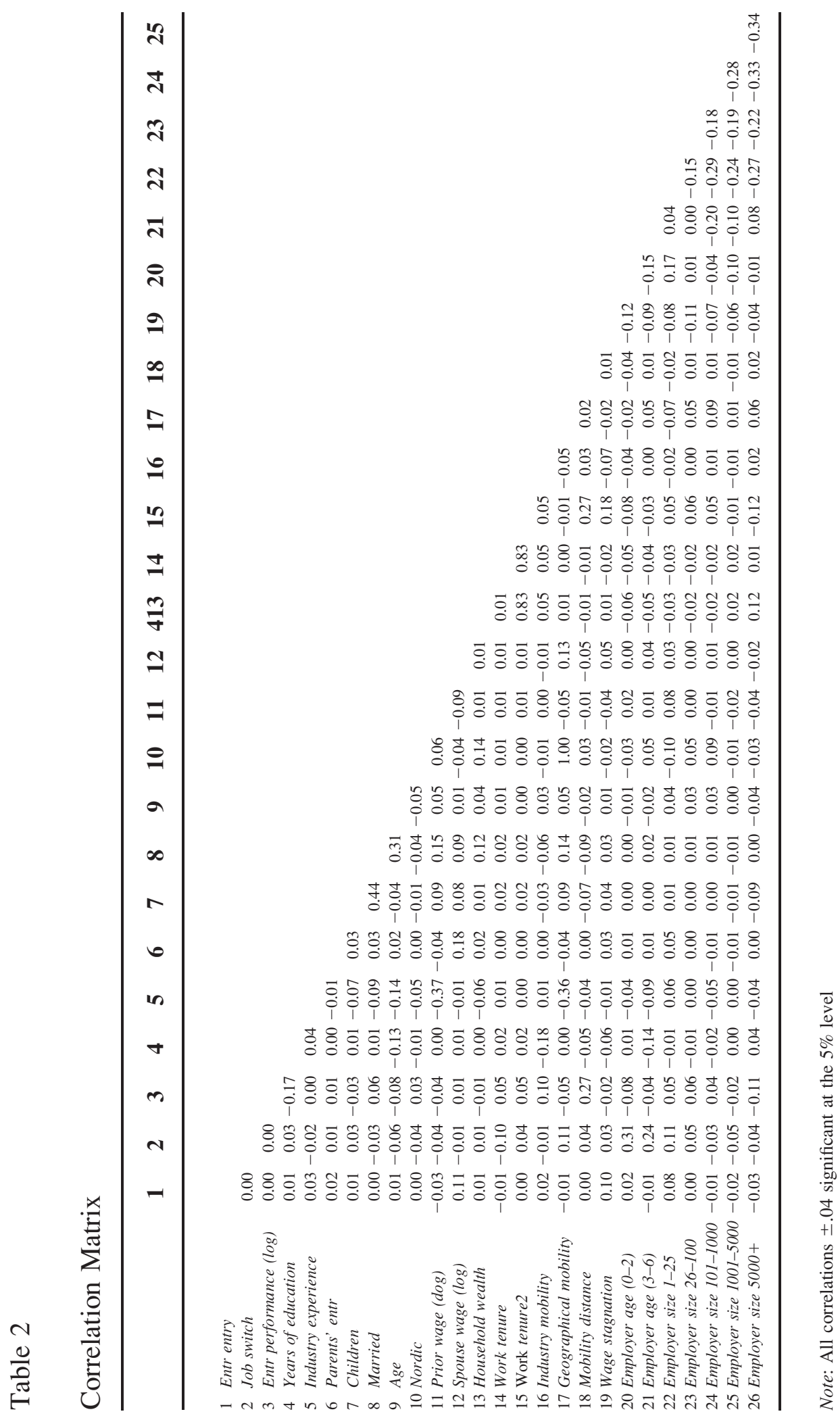


Cox Models With Frailty on Entrepreneurial Entry (Compared to Job Switch)

\begin{tabular}{|c|c|c|}
\hline & Entrepreneurial entry & Job switch \\
\hline Years of education & $1.009(.013)$ & $1.217 * * *(.002)$ \\
\hline Industry experience & $1.128 * * *(.014)$ & $1.002(.071)$ \\
\hline Parents' entrepreneurship & $1.229 *(.398)$ & $.883(.085)$ \\
\hline Children & $1.026(.022)$ & $.996(.006)$ \\
\hline Married & $.997(.003)$ & $1.170 * * *(.011)$ \\
\hline Age & $.917+(.046)$ & $1.304 * * *(.007)$ \\
\hline Nordic & $.919(.067)$ & $1.015^{* * *}(.002)$ \\
\hline Wage $(\log )$ & $.910 * * *(.003)$ & $1.069 * * *(.012)$ \\
\hline Spouse wage (log) & $1.128 * * *(.007)$ & $1.066^{* * *}(.011)$ \\
\hline Household wealth & $1.146(.111)$ & $.973 * * *(.004)$ \\
\hline Work tenure & $1.088 * * *(.377)$ & $1.325^{* * *}(.002)$ \\
\hline Work tenure 2 & $.984 * * *(.015)$ & $1.183^{* * *}(.004)$ \\
\hline Wage trend & $.983^{* *}(.019)$ & $.972 * * *(.014)$ \\
\hline \multicolumn{3}{|l|}{ Mobility effects } \\
\hline Industry mobility $\mathbf{H 1}$ & $1.268 * * *(.018)$ & $.095^{* *}(.004)$ \\
\hline Number of geographic moves $\mathbf{H 2 a}$ & $1.148 * * *(.188)$ & $1.307 * * *(.002)$ \\
\hline Geographical mobility distance $\mathbf{H 2 a}$ & $1.036(.004)$ & $1.192^{* * *}(.029)$ \\
\hline \multicolumn{3}{|l|}{ Employer effects } \\
\hline Employer age (0-2) & $1.249 *(.074)$ & $2.074 * * *(.033)$ \\
\hline Employer age (3-6) & $.975^{* *}(.098)$ & $1.934 * * *(.047)$ \\
\hline Employer size 1-25 & $1.305^{* * *}(.177)$ & $1.132 * * *(.009)$ \\
\hline Employer size 26-100 & $.895 * * *(.130)$ & $1.141^{* * *}(.012)$ \\
\hline Employer size 101-1,000 & $.857 * * *(.079)$ & $.826^{* * *}(.008)$ \\
\hline Employer size 1,001-5,000 & $.728 * * *(.012)$ & $.833^{* * *}(.009)$ \\
\hline$\theta$ (fraility variance) & $.152(.054)$ & $.211(.088)$ \\
\hline LR-test of $\theta=0$ & $54.19 * * *$ & $201.30^{* * *}$ \\
\hline Time-year obs. & $1,540,077$ & $1,540,077$ \\
\hline Individual obs. & 230,362 & 230,362 \\
\hline Entries/Job switches & 2,549 & 139,467 \\
\hline BIC value & $48,650.46$ & $122,187.10$ \\
\hline Log likelihood & $-24,169.04$ & $-643,400.84$ \\
\hline
\end{tabular}

Notes: Coefficients in hazard rate format, year dummies included $+p<.10, * p<.05, * * p<.01, * * * p<.001$ (two-tailed)

Second, we examine the hypothesized effects of geographical mobility on entrepreneurial entry. Model one of Table 3 shows that the coefficients for geographical mobility is a strong predictor of entrepreneurial entry $(p>.001)$, while mobility distance is not significant $(p<.10)$. The hazard rate of 1.148 indicates that for each additional move across municipalities in the preceding 5 years, the likelihood of entering entrepreneurship increases by $14.8 \%$. When comparing these to the corresponding coefficients in column two of Table 3, we see that both number of geographic moves (HR: 1.307, $p>.001$ ) and mobility distance (HR: 1.192, $p>.001$ ) are also associated with subsequent likelihood of job switch $(p>.01)$. This indicates that the potential effect of geographic mobility on entrepreneurship is part of an overall pattern related to overall likelihood of switching jobs in general. In fact, the effects of both variables for job switch are markedly larger than the corresponding effects for entrepreneurial entry. Together, these results provide mixed evidence in favor of hypothesis $2 \mathrm{a}$ but not for hypothesis $2 \mathrm{~b}$. In the Discussion section we return to consider the potential difference between geographical mobility and mobility distance. 
While we did not theorize on the potential effect of the prior workplace and wages for individuals' probability to engage in entrepreneurship, we note some marked differences in likelihood of entrepreneurial entry depending on the size of the previous employer and prior wages. First, we note that prior wages decrease the likelihood of entrepreneurial entry (HR: .910, $p>.001$ ) but marginally increase the likelihood of switching jobs (HR: $1.069, p>.001)$. Spouse's wage increase both the likelihood of entrepreneurial entry and switching jobs (HR: 1.128 and 1.066, both at $p>.001$ ). Both indicate that opportunity costs in terms of one's own and spouse's wage affect the opportunity cost of engaging in entrepreneurship. Our variable specifically designed to proxy for the opportunity cost of leaving employment-Wage trend - is shown to decrease the likelihood of entrepreneurial entry (HR: .983, $p>.01$ ) and the likelihood of switching jobs (HR: .972, $p>.001$ ). This indicates that individuals with rising wages are less likely to engage in entrepreneurship as well as to switch jobs.

We also examine the effects of former employer size on entrepreneurial entry, compared to the likelihood of switching jobs. Under the heading "employer effects" in Table 3 we see that the dummy variable for Employer size 1-25 is positively related to entrepreneurship while the other employer size variables are all negative (all significant at $p>$.001). Similar to Nanda and Sørensen (2010), we find that the threshold at which the positive effect of employer size on entrepreneurial entry becomes negative occurs after the twenty-sixth employee. When comparing these results to the corresponding coefficients in column two of Table 3, we see that the dummy variables for Employer size 1-25 and Employer size 26-100 are also positively related to the likelihood of job switch $(p>.001)$ while the other employer size variables are negatively related to the likelihood of job switch $(p>.001)$. These comparisons indicate that the associations between former employer size and entrepreneurial entry may be part of an overall pattern related to job mobility, depending on whether an individual has recently worked in a small or large firm.

Our theory posits counterarguments for why mobility would affect an individual's probability to engage in entrepreneurship relating to the "taste for variety" and "misfits" reasons rather than the accumulation of specific human capital or the exposure to knowledge spillovers. If that is so, we would expect mobility to increase the probability to engage in entrepreneurship but not to enhance entrepreneurial performance. We, therefore, turn to investigate the effect of mobility for earnings in entrepreneurship.

Table 4 shows models of entrepreneurial earnings, based on all individual-year observations available in the data set of individuals entering entrepreneurship during the time period 1995-2002. We show two different specification of the earnings models in Table 4 , pooled OLS (column 1), and panel data models estimated with random effects (column 2 ). In this model, we focus on the mobility variables, defined identically as in the model of entrepreneurial entry. We see that the variable industry mobility is positive but not significantly related to subsequent entrepreneurial performance in neither the OLS (1.126, $p<.10)$ nor the random effects panel model $(1.042, p<.10)$. This supports hypothesis $3 a$ 's argument about a negative or zero relationship between industry mobility and entrepreneurial performance. The variable number of geographic moves is weakly positively related to subsequent entrepreneurial performance in the OLS $(1.031, p>.05)$ but not in the random effects panel model $(1.017, p<.10)$. This supports also hypothesis $3 \mathrm{~b}$ 's argument about a negative or zero relationship between number of geographic moves and entrepreneurial performance. However, the variable mobility distance is positively related to entrepreneurial performance in both the OLS $(1.229, p>.001)$ and also so in the random effects panel model $(1.148, p>.05)$. Taken together, these effects suggest that knowledge flow is not the only explanation for mobility into entrepreneurship. If that 


\section{Table 4}

\section{Regression Models on Entrepreneurial Earnings (Log)}

\begin{tabular}{|c|c|c|}
\hline & OLS & Random effects panel \\
\hline Years of education & $1.277 * *(.101)$ & $.926 *(.035)$ \\
\hline Industry experience & $.437 * * *(.044)$ & $.184 * * *(.019)$ \\
\hline Parents' entrepreneurship & $1.101 *(.043)$ & $.998(.003)$ \\
\hline Children & $1.063(.105)$ & $1.029(.057)$ \\
\hline Married & $1.486^{* * *}(.278)$ & $1.578 * * *(.763)$ \\
\hline Nordic & $.999(.004)$ & $.997(.003)$ \\
\hline Spouse wage & $1.006(.026)$ & $1.033(.035)$ \\
\hline Household wealth & $1.001(.010)$ & $.993(.011)$ \\
\hline Work tenure & $.924 * * *(.012)$ & $.931 * * *(.007)$ \\
\hline Work tenure2 & $1.006(.024)$ & $.999(.015)$ \\
\hline \multicolumn{3}{|l|}{ Mobility effects } \\
\hline Industry mobility $\mathbf{H 3 a}$ & $1.126(.069)$ & $1.042(.039)$ \\
\hline Number of geographic moves $\mathbf{H 3 \mathbf { b }}$ & $1.031 *(.013)$ & $1.017(.019)$ \\
\hline Mobility distance & $1.229 * * *(.051)$ & $1.148 *(.078)$ \\
\hline \multicolumn{3}{|l|}{ Employer effects } \\
\hline Employer age (0-2) & $.827 *(.074)$ & $.842(.245)$ \\
\hline Employer age (3-6) & $1.033(.035)$ & $1.035(.057)$ \\
\hline Employer size 1-25 & $1.531 *(.278)$ & $.993(.011)$ \\
\hline Employer size 26-100 & $1.144 *(.070)$ & $1.123 *(.067)$ \\
\hline Employer size 101-1,000 & $.182^{* * *}(.019)$ & $.121 * * *(.024)$ \\
\hline Employer size 1,001-5,000 & $1.219^{* * *}(.055)$ & $1.169 * * *(.036)$ \\
\hline Mills ratio & $.224(.091)$ & $.394(.152)$ \\
\hline Intercept & $9.142 * * *(.177)$ & $7.321 * * *(.231)$ \\
\hline Observations & 15,213 & 15,213 \\
\hline Overall R2 & .195 & .169 \\
\hline R2 (between) & $\mathrm{n} / \mathrm{a}$ & .164 \\
\hline R2 (within) & $\mathrm{n} / \mathrm{a}$ & .036 \\
\hline
\end{tabular}

Notes: Standard errors clustered around individuals, year dummies included.

$* p<.05, * * p<.01, * * * p<.001$ (two-tailed)

would have been the case, we would have expected people that switch employers and move more often to exhibit higher performance in entrepreneurship.

The selection equation (Mills ratio) for entry into entrepreneurship is not significantly related to subsequent entrepreneurial performance in neither the $\operatorname{OLS}(.224, p<.10)$ nor the random effects panel model $(.394, p<.10)$.

\section{Robustness Tests}

A potential confounding explanation to our findings is the possibility that people leave large and small firms because of a downturn in these firms, or leave their current region of residence due to exogenous economic shocks. To investigate these possibilities, we re-estimated Table 3 including two additional variables: (1) a dummy variable coded " 1 " if the prior employer experienced a drop in turnover by $20 \%$ or higher compared with the preceding year, and (2) a variable denoting the difference in regional unemployment rate and unemployment rate in other regions. The results (available on request) show a decrease in effect size of the employer variables when a dummy variable for "drop in 
turnover" in introduced, but the employer variables are still significant at the $5 \%$ level or below. Results remained unchanged upon inclusion of the unemployment rate variable.

A second potentially confounding explanation to our findings is the possibility that individuals' decisions to move and to switch jobs are co-determined, which may introduce an endogeneity bias. Even though economic geography research indicates that the correlation between taking a new job and geographic mobility is low (Korpi et al., 2011), this does not rule out endogeneity concerns. We, therefore, conducted additional robustness tests: First, instead of defining our two variables denoting geographic mobility as "the number of times/the distance an individual has moved between municipalities during the past 5 years" (accumulated lagged variables constructed to minimize simultaneity bias), we operationalized these two variables as "the number of times/the distance an individual has moved between municipalities between five and two years ago" to have a longer time between mobility and our tests of entry. This did not alter the signs or significance levels of our hypothesized effects. As a second robustness test, we reestimated Table 3 using alternative specification to the exact Cox with unobserved heterogeneity. We estimated Cox models with standard errors clustered around individuals (which do not accommodate LR testing of the theta variable) and Cox models which accommodate for tied events in the data (STATA's exactp module). We also estimated piecewise exponential models. The significance level and direction of all hypothesized effects remained identical in these models, indicating that our results are robust to alternative specifications.

\section{Discussion}

We extend prior research by studying the mobility patterns of firm founders and where firm founders emanate from. We theorized that the resources and skills (i.e., knowledge) gained through exposure to different industries and geographical domains positively influence the likelihood of entry. As a counterfactual we posited that if there is a positive association between mobility and entrepreneurial entry but not between mobility and entrepreneurial performance, these explanatory mechanisms might not be related only to accumulation of knowledge from mobility, but may equally well be driven by alternative mechanisms such as an individual's "taste for variety" or individuals being ill matched to the labor market and thus having lower opportunity costs. Our empirical results indicate that prior industry and geographic mobility enhance the chance of entry into entrepreneurship, but do not affect entrepreneurial performance.

We contribute to both entrepreneurship and organizational research discussing the potentially distinctive mechanisms underlying individuals' mobility. First, our scrutiny of mobility patterns as a mechanism for knowledge accumulation and spillover of entrepreneurial opportunities and resources suggests that the findings on labor market mobility and knowledge flows in markets and industries may not be the only representative mechanism for individuals' entrepreneurship (Agarwal et al., 2004; Klepper \& Sleeper, 2005). Our findings on firm founding and mobility thus challenge the literature on knowledge spillovers as the only crucial mechanism for entrepreneurship. This literature often infers knowledge flows from mobility, without accounting for the fact that mobility does not necessary imply knowledge flows (Anand et al., 2015).

Second, although not hypothesized in our article, we advance an interesting empirical puzzle: While people with higher past industry and geographic mobility and experience from working in small firms may be prone to set up new organizations, their entrepreneurial efforts often reveal limited success. Instead, a firm founder's background in larger 
organizations matters more for entrepreneurial performance. This result on the relative benefits of a large firm background are at odds with those reported by Sørensen and Phillips (2011) in their study of the self-employed in Denmark in 1988, 1990, and 1992, but consistent with Hvide's (2009) study of Norwegian spinoffs (1994-2002) and Andersson and Klepper's (2013) study on spinoffs in Sweden 1997-2005. Two theoretical explanations may clarify the importance of "a large firm background" for entrepreneurial performance: one located at the level of the organization and one at the individual level. At the organizational level, the networks and experiences accumulated by employment in larger firms may enhance external legitimacy attributed to individuals entering into entrepreneurship from well-reputed large organizations. Well-known "entrepreneurial hubs" such as Fairchild semiconductors may serve as a better springboard for successful entrepreneurial activity than to engage in arbitrage based on a diverse set of labor market experiences (Burton, Sørensen, \& Beckman, 2002). On the individual level, a "taste for variety" in occupational tasks - or simply being a misfit into the "traditional" labor market demands-may encourage individuals to switch employers and workplaces more often, as well as influence the probability that they will themselves engage in organization building. However, this does not necessarily make them successful entrepreneurs. Since the accumulation of knowledge and resources are at the heart of entrepreneurship these results are pivotal in gaining a more thorough understanding of what organizational background fosters or inhibits entrepreneurship. Our arguments advocate research to look not only at knowledge-spillover theories to explain entrepreneurial outcomes of individual mobility. Without a proper understanding of counterfactual arguments, "simpler" selection or situational mechanisms such as a taste for variety or low opportunity costs may be equally valid explanations.

Our findings are of interest for policy makers seeking to enhance the level of entrepreneurship in their region or economy. To date, most such efforts have been directed toward increasing the quantity rather than the quality of entrepreneurial efforts (Shane, 2009). Our findings imply that policy makers seeking to enhance the quality of entrepreneurial efforts should try to explore mechanisms that offer increased support and incentives to skilled people employed in large firms to found organizations. One such incentive to consider may be the easing of non-compete covenants (Stuart \& Sorenson, 2003). Firms whose founders come from larger firms might also be more prone to launch innovations, employ others, and provide other societal spillovers.

\section{Limitations and Future Research}

Our study comes with limitations, several of which point to ideas for further investigating the relationship between mobility and entrepreneurship. First, our research design was crafted in such a way that it allows investigation of both entry and performance as outcomes of mobility. The results highlight that mobility may not bring about the benefits in terms of experiences and skills as depicted by knowledge-spillover theories of entrepreneurship, but may equally well be the result of an innate taste for variety or a generally poor ability which lowers labor market opportunity costs (Åstebro et al., 2011). To achieve a clear answer to the question whether people with a high degree of mobility simply are endowed with a taste for job change, research may utilize psychometric tests correlated with a taste for variety (Evans \& Leighton, 1989).

Second, while our measures of past employment indicate interesting nonlinearity in that prior employment in smaller and younger organizations increases likelihood of entry but does not affect performance our research design puts a limit on the scale of 
organization age that we could measure. The measures of employer age amounts rather to very young (0-2) and quite young (3-6) firms rather than young and old firms. While this makes our findings conservative in that we effectively lower the risk of erroneously attributing an age effect where in reality there is none (type-two errors), it limits the generality of the results.

Third, while we observe the complete labor market history of individuals in our sample, the sample is limited to knowledge-intensive industries. Obviously, employee mobility as a source of knowledge spillovers as well as an individual's taste for variety or being a "misfit" exists in other sectors as well, representing a limitation to our findings (Andersson \& Klepper, 2013). Investigations of various types of industry, and geographical mobility for entrepreneurial entry and performance represent important avenues of research.

Fourth, in order not to introduce additional heterogeneity, we restricted our sample only to include men. This represents a clear limitation of our study results.

\section{Conclusion}

Our results speak to the importance of research in the intersection of micro-oriented research on entrepreneurial processes, and macro-oriented research on organizational birth and evolution. For micro-oriented research, our study highlights the importance of measuring career experience and mobility on a number of dimensions, with a caution that resources and knowledge may not be automatically inferred from mobility without considering simple counterfactuals such as, for example, an innate taste for variety. For macro-oriented research, our study points out the importance of considering individual firm founders' past experience for both new venture creation and entrepreneurial performance.

Individual mobility is intimately related to both entrepreneurial entry and performance. By positing counterfactual reasons for why mobility across industries and regions affects entrepreneurship, we emphasize that the association between mobility and entrepreneurship is not necessarily evidence of the accumulation of resources and skills as suggested by the theories of knowledge-based entrepreneurship. We show how the implication of prior employment contexts is broader than the contents of the most recent job and perpetuate beyond that of the founding of a new independent venture.

\section{Appendix}

\section{Knowledge-Intensive Industries}

\begin{tabular}{|c|c|c|}
\hline Sector & Description & SIC codes \\
\hline & Manufacturing & 15 to 37 \\
\hline (1) & High-tech manufacturing & 30,32 , and 33 \\
\hline \multirow[t]{2}{*}{ (2) } & Medium high-tech manufacturing & $24,29,31,34$, and 35 \\
\hline & Services & 50 to 99 \\
\hline (3) & High-tech services & $64,72,73$ \\
\hline (4) & Business services & $61,62,70,71,74$ \\
\hline (5) & Financial services & $65,66,67$ \\
\hline (6) & Other knowledge-intensive services & $80,85,92$ \\
\hline
\end{tabular}




\section{REFERENCES}

Acs, Z.J., Braunerhjelm, P., Audretsch, D.B., \& Carlsson, B. (2009). The knowledge spillover theory of entrepreneurship. Small Business Economics, 32(1), 15-30.

Agarwal, R., Audretsch, D.B., \& Sarkar, M.B. (2007). The process of creative construction: Knowledge spillovers, entrepreneurship, and economic growth. Strategic Entrepreneurship Journal, 1(3-4), 263-286.

Agarwal, R., Echambadi, R., Franco, A., \& Sarkar, M.B. (2004). Knowledge transfer through inheritance: Spin-out generation, growth and survival. Academy of Management Journal, 47(4), 501-522.

Aldrich, H. \& Ruef, M. 2006. Organizations evolving. London: Sage.

Aldrich, H.E. \& Kenworthy, A. (1999). The accidental entrepreneur: Campbellian antinomies and organizational foundings. In J. A. C. Baum \& B. McKelvey (Eds.), Variations in organization science. Newbury Park, CA: Sage.

Amit, R., Müller, E., \& Cockburn, I. (1995). Opportunity costs and entrepreneurial activity. Journal of Business Venturing, 10(2), 95-106.

Anand, J., Mulotte, L., \& Ren, C.R. (2015). Does experience imply learning? Strategic Management Journal, doi:10.1002/smj.2401.

Andersson, M. \& Klepper, S. (2013). Characteristics and performance of new firms and spinoffs in Sweden. Industrial Corporate Change, 22(1), 245-280.

Arum, R. \& Müller, W. (2004). The reemergence of self-employment: A comparative study of selfemployment dynamics and social inequality. Princeton, NJ: Princeton University Press.

Åstebro, T., Chen, J., \& Thompson, P. (2011). Stars and misfits: Self-employment and labor market frictions. Management Science, 57(11), 1999-2017.

Åstebro, T. \& Thompson, P. (2011). Entrepreneurs, Jacks of all trades or Hobos? Research Policy, 40, 637-649.

Audretsch, D.B. \& Keilbach, M. (2007). The theory of knowledge spillover entrepreneurship. Journal of Management Studies, 44(7), 1242-1254.

Bates, T. (1990). Entrepreneur human capital inputs and small business longevity. Review of Economics and Statistics, 72(4), 551-559.

Brüderl, J., Preisendörfer, P., \& Ziegler, R. (1992). Survival chances of newly founded business organizations. American Sociological Review, 57(2), 227-242.

Burton, M.D., Sørensen, J.B., \& Beckman, C.M. (2002). Coming from good stock: Career histories and new venture formation. Research in the Sociology of Organizations, 19, 229-262.

Carroll, G.R. \& Mosakowski, E. (1987). The career dynamics of self-employment. Administrative Science Quarterly, 32(4), 570-589.

Cooper, A.C. (1985). The role of incubator organizations in the founding of growth-oriented firms. Journal of Business Venturing, 1(1), 75-86.

Dahl, M.S. \& Reichstein, T. (2007). Are you experienced? Prior experience and the survival of new organizations. Industry and Innovation, 14, 497-497.

Davidsson, P. (2004). Researching entrepreneurship. New York: Springer.

Delmar, F. \& Wennberg, K. (2010). Knowledge intensive entrepreneurship: The birth, growth and demise of entrepreneurial firms. Cheltenham, UK: Edward Elgar. 
Dencker, J.C., Gruber, M., \& Shah, S.K. (2009). Pre-entry knowledge, learning, and the survival of new firms. Organization Science, 20(3), 516-537.

Eckhardt, J.T. \& Shane, S.A. 2011. Industry changes in technology and complementary assets and the creation of high-growth firms. Journal of Business Venturing, 26(4), 412-430.

Elfenbein, D.W., Hamilton, B.H., \& Zenger, T.R. (2010). The small firm effect and the entrepreneurial spawning of scientists and engineers. Management Science, 56, 659-681.

Evans, D.S. \& Leighton, L.S. (1989). Some empirical aspects of entrepreneurship. The American Economic Review, 79(3), 519-535.

Folta, T.B., Delmar, F., \& Wennberg, K. (2010). Hybrid entrepreneurship. Management Science, 56(2), 253-269.

Franco, A.M. \& Filson, D. (2006). Spin-outs: Knowledge diffusion through employee mobility. RAND Journal of Economics, 37(4), 841-860.

Ghiselli, E.E. (1974). Some perspectives for industrial psychology. American Psychologist, 29(2), 80-87.

Gimeno, J., Folta, T.B., Cooper, A.C., \& Woo, C.Y. (1997). Survival of the fittest? Entrepreneurial human capital and the persistence of underperforming firms. Administrative Science Quarterly, 42(4), 750-783.

Götzfried, A. (2004). European employment increasing in services and especially in knowledge-intensive services. Statistics in Focus: Science and Technology, October 10. Luxembourg, UK: Catalogue KS-NS04-010-EN-N, Eurostat.

Hedström, P. \& Swedberg, R. 1998. Social mechanisms: An analytical approach to social theory. Cambridge, UK: Cambridge University Press.

Helfat, C. \& Lieberman, M. (2002). The birth of capabilities: Market entry and the importance of prehistory. Industrial and Corporate Change, 11(4), 725-760.

Hvide, H.K. (2009). The quality of entrepreneurs. Economic Journal, 119, 1010-1035.

Kim, P. \& Aldrich, H.E. (2007). How social networks affect entrepreneurial team formation and search. Strategic Entrepreneurship Journal, 1(1), 147-165.

Klepper, S. \& Sleeper, S. (2005). Entry by spinoffs. Management Science, 51(8), 1291-1306.

Korpi, M., Clark, W.A.V., \& Malmberg, B. (2011). The urban hierarchy and domestic migration: The interaction of internal migration, disposable income and the cost of living, Sweden 1993-2002. Journal of Economic Geography, 11(6), 1051-1077.

Lancaster, T. (1979). Econometric methods for the duration of unemployment. Econometrica, 47(4), 939-956.

Lee, L.F. (1983). Generalized econometric models with selectivity. Econometrica: Journal of the Econometric Society, 51(2), 507-512.

Nanda, R. \& Sørensen J.B. (2010). Workplace peers and entrepreneurship. Management Science, 56(7), $1116-1126$.

Özcan, S. \& Reichstein, T. (2009). Transition to entrepreneurship from the public sector: Predispositional and contextual effects. Management Science, 55(4), 604-618.

Parker, S.C. (2005). The economics of self-employment and entrepreneurship. Cambridge: Cambridge University Press.

Saxenian, A. (2006). The new argonauts: Regional advantage in a global economy. Cambridge, MA: Harvard University Press. 
Shane, S. (2000). Prior knowledge and the discovery of entrepreneurial opportunities. Organization Science, 11(4), 448-469.

Shane, S. (2009). Why encouraging more people to become entrepreneurs is bad public policy. Small Business Economics, 33(2), 141-149.

Sørensen, J. (2007a). Bureaucracy and entrepreneurship: Workplace effects on entrepreneurial entry. Administrative Science Quarterly, 52(3), 387-412.

Sørensen, J. (2007b). Closure and exposure: Mechanisms in the intergenerational transmission of selfemployment. Research in the Sociology of Organizations, 25, 83-124.

Sørensen, J. \& Fassiotto, M. (2011). Organizations as fonts of entrepreneurship. Organization Science, 22(5), 1322-1331.

Sørensen, J. \& Phillips, D. (2011). Competence and commitment: Employer size and entrepreneurial endurance. Industrial and Corporate Change, 20(5), 1277-1304.

Sørensen, J. \& Sharkey A. (2014). Entrepreneurship as a mobility process. American Sociological Review, 79(2), 328-349.

Sørenson, O. \& Audia, P. (2000). The social structure of entrepreneurial activity: Geographic concentration of footwear production in the United States, 1940-19891. American Journal of Sociology, 106(2), 424-462.

Stuart, T. \& Sorenson O. (2003). Liquidity events and the geographic distribution of entrepreneurial activity. Administrative Science Quarterly, 48(2), 175-201.

Ucbasaran, D., Westhead, P., \& Wright, M. (2009). The extent and nature of opportunity identification by experienced entrepreneurs. Journal of Business Venturing, 24, 99-115.

van Praag, C. (2003). Business survival and success of young small business owners. Small Business Economics, 21(1), 1-17.

Van Praag, C. \& Cramer, J. (2001). The roots of entrepreneruship and labour demand: Individual ability and low risk aversion. Economica, 68(269), 45-62.

Wright, M. (2011). Entrepreneurial mobility, In D. Bergh \& D. Ketchen (Eds.), Research methodology in strategy and management (Vol. 6, pp. 137-159). Bingley, UK: Emerald Group Publishing.

Lars Frederiksen is a professor at Department of Management, BSS Aarhus University, Denmark.

Karl Wennberg is a professor at Linköping University, Institute for Analytical Sociology (IAS) and affiliated with the Ratio Institute.

Chanchal Balachandran is a postdoctoral fellow at Institute for Analytical Sociology (IAS), Linköping University.

We are grateful for comments provided by the three special issue editors and referees, Brice Dattee, Nicolai Foss, Martin Korpi, Steffen Korsgaard, Andrea Mina, Mike Wright, Tiantian Yang, Linus Dahlander, Rosemarie Ziedonis, and participants at EMLYON Business School seminar 2011, the 2010 Copenhagen Business School workshop on Strategic Entrepreneurship, the 2011 DRUID Summer conference in Copenhagen, and the 2012 Academy of Management Meeting in Boston. Funding was provided by the Swedish Research Council (DNR 340-2013-5460) and Riksbankens Jubileumsfond (DNR M12-0301:1). All authors contributed equally to this work. Any errors remain ours alone. 